\title{
Computer-aided design of cyber-physical building systems
}

\author{
Pavel Chelyshkov* \\ Moscow State University of Civil Engineering, Yaroslavskoe shosse, 26, Moscow, 129337, Russia
}

\begin{abstract}
At present, an increasing number of researchers and specialists in the construction industry come to the opinion that it is advisable to use a number of technologies (BIM, Smart City, Big Data, IOT and others) in the practice of construction (in the broad sense of this concept), which are united by the concept of the Fourth Industrial Revolution. The result of the implementation of these technologies in the construction should be the transition to the widespread use of cyber-physical systems.

The problem of using information technologies in construction today is not due to the lack of this process as such, but to the lack of consistency and consistency in it. Fragmentary nature of the application, inconsistency of the applied technologies at different levels of management and at different stages of the life cycle of construction projects sharply reduce the potential positive effect of informatization and building automation. At the same time, the concept of cyber-physical systems, that is, the integration at the system level of physical processes and controls has proven effective in industrial production.

The approaches to ensuring the processes of designing cyber-physical building systems through the development and application of General mathematical models for the processes of data exchange and management are considered. The presented models of data exchange and management of cyber-physical building systems describe the processes implemented at each stage of the life cycle of cyber-physical building systems. Functional blocks of the considered models allow to describe the processes of data collection, storage and processing on the current and past stages of the life cycle of cyber-physical construction systems. The presented models are the elements of mathematical support of the processes of designing cyberphysical building systems, which determine the processes of information exchange and management between the structures of cyber-physical building systems of different levels of hierarchy in the full life cycle.
\end{abstract}

As K. Maintser notes in the article "Exploring complexity", the processes of cognitive systems, as opposed to classical artificial intelligence, may be considered in isolation from the physical system and its integration into the environment. [1]

The above mentioned also applies to the "Globalized Internet World". Despite the fact that now there is a traditional separation between the physical ("real") and virtual world, in many branches of activity (such as medicine and engineering), actions in physical ("real")

\footnotetext{
${ }^{*}$ Corresponding author: ChelyshkovPD@mgsu.ru
} 
world are carried out with the support of virtual instruments. In particular, "the operation is accompanied by a virtual image of the organ with accurate information and measurement data, ensuring the accuracy of the surgical treatment." Thus, we can talk about the expansion of the physical world through the use of virtual reality - the "virtual reality" concept was replaced by the "augmented reality" concept. [1]

As an example of local cyber physical systems in construction, K. Maintser gives mechatronic systems that integrate mechanical and electronic systems (including related sensor technology, that is control and management system), also from this perspective "smart home" equipped with sensors and cars with navigation systems and advanced driver-assistance systems are considered, representing the software and hardware to ensure the safety of people and engineering systems in the environment. [1]

The "building system" and "cyber physical building system" concepts are defined in [2]. Based on these definitions, a cyber physical building system (hereinafter referred to as CPBS) is "elements, facilities, construction complex, computing resources integrated into the included physical processes" [2]. That is, CPBS integrates the physical layer (building systems) and management information systems, including decision-making mechanisms.

Cyber physical systems integrate the cybernetic origin, computer hardware and software technologies, quality new executive mechanisms built into their surrounding media and able to perceive its changes, learn independently and adapt. The key model in cyber physical systems is the model used in the control system - the cyber physical system operation depends on the way it is relevant to reality. Today, this is not just a threedimensional picture of buildings and structures and the earth or underwater surface - this is already a multidimensional representation. Here the building information model (BIM) is combined with the production information model (PIM), forming a completely new quality. [3]

The above-mentioned leads to the conclusion that the most important element of the system for constructing and computer-aided design of the CPBS is the interaction model (data exchange) of the information management system and physical systems that are elements of the CPBS [4-14].

The results of the research are provided below, which made it possible to form 2 models - the general model of CPBS data exchange and the general model of CPBS data management, representing a sufficiently formalized structure for building the full life cycle of the CPBS.

In the framework of the study, construction systems are classified according to the requirements of the construction facility that they meet. The requirements include design parameters, water supply, ensuring micro-climate, lighting, electricity, gas supply, communications, transport, security, ensuring fire safety.

Accordingly, with the identified types of requirements, the following construction systems are considered: condition and management of structures monitoring system (for the first type of requirements), a system for producing (extracting) water, a system for preparing (purifying) water, a water delivery system (pumping stations), a water distribution system (water supply network), a system for collecting and cleaning rainwater, water recycling system, sewage system, storm water sewer system, wastewater treatment system (for the second type of requirements), heat production (generation) system, heat delivery system (heat supply), cold production system, system cold delivery, heating system, ventilation system, air conditioning system (for the third type of requirements), translucent structures, electric lighting system, daylight system using light guides (for the fourth type of requirements), electric power generation (generation) system, electric power transformation system, power storage system, power distribution system (for the fifth type of requirements), gas storage system, gas supply system, gas distribution system (for the sixth type of requirements), telephone communication system, telegraph communication 
system, radio communication system, television communication system, satellite communication system, computer communication system, fax system (for the seventh type of requirements), vertical transport systems, loading and unloading mechanisms, vehicles (for the eighth type of requirements), alarm system, access control system, fence intruder detection (for the ninth type of requirements), fire extinguishing systems, fire alarm systems (for the tenth type of requirements).

The general model of CPBS data exchange is given in Fig. 1. The model has a block structure. The functional blocks of the model are numbered as follows: n.m.l.z, where $n-$ CPBS number (in the CPBS group under consideration), $m$ - CPBS life cycle stage, $l-$ hierarchy level (the figure shows specific values), $\mathrm{z}$ is the block number within the simulated stage of the life cycle of the CPBS (the figure shows the specific values).

The functional blocks of the imitation of building systems form the values of the controlled parameters (parameters of the building systems) (s), taking into account the incoming disturbing (w) and controlling $(u)$ actions. The data structure of the functional block for process simulation is (1).

$$
A \bar{S}+B \bar{U}+C \bar{W}=p \bar{S}
$$

where $p$ - Laplace operator;

$\bar{S}=\left(\begin{array}{c}s_{1} \\ s_{2} \\ \ldots \\ s_{r}\end{array}\right)$ - controlled parameters (building systems parameters) vector;
$r-$ number of controlled parameters (building systems parameters) considered;

$\bar{U}=\left(\begin{array}{c}u_{1} \\ u_{2} \\ \cdots \\ u_{d}\end{array}\right)$ - control actions vector;

$\mathrm{d}$ - number of considered control actions;

$\bar{W}=\left(\begin{array}{c}w_{1} \\ w_{2} \\ \ldots \\ w_{z}\end{array}\right)-$ disturbing actions vector;

$z$ - number of disturbing actions considered;

$A=\left(\begin{array}{ccc}a_{11} & \ldots & a_{1 r} \\ \ldots & \ldots & \ldots \\ a_{r 1} & \ldots & a_{r r}\end{array}\right)$ - building systems parameters matrix;

$B=\left(\begin{array}{ccc}b_{11} & \ldots & b_{1 d} \\ \ldots & \ldots & \ldots \\ b_{r 1} & \ldots & b_{r d}\end{array}\right)-$ control actions matrix

$C=\left(\begin{array}{ccc}c_{11} & \cdots & c_{1 z} \\ \cdots & \cdots & \cdots \\ c_{r 1} & \cdots & c_{r z}\end{array}\right)-$ disturbing actions matrix 


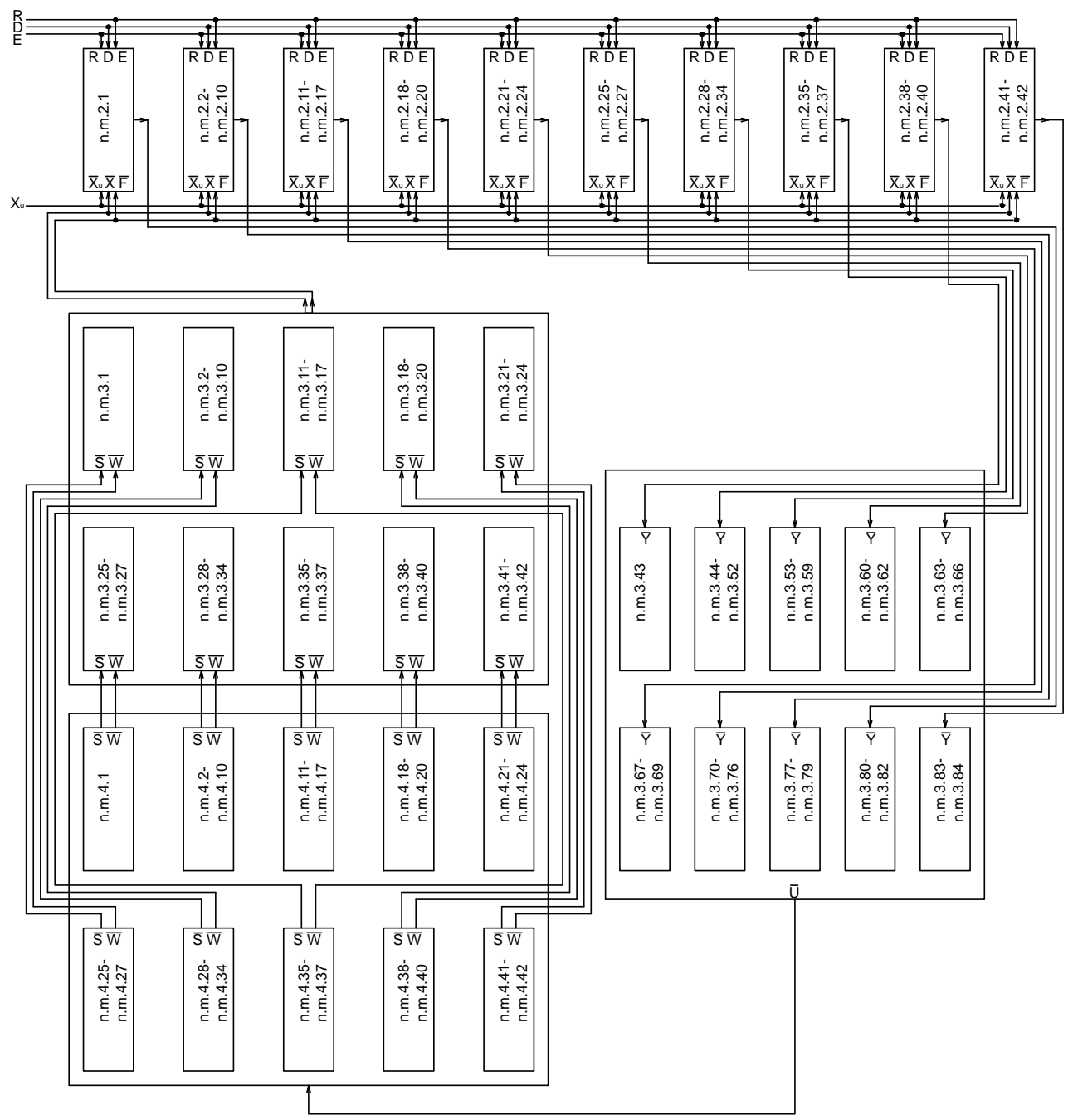

Fig. 1. CPBS data exchange general model

Functional blocks of parameters control are designed to simulate the process of data conversion coming from the physical level of the CPBS in the signals available for use at the CPBS control level. The considered functional blocks provide a simulation of the formation of data packets, time delays and distortions in the processes of information transfer.

Functional dependencies of the parameters control functional block are as follows (2 and 3).

where $t$ is time;

$$
\bar{X}=\left(\begin{array}{c}
x_{1}\left(s_{1}, t\right) \\
x_{2}\left(s_{2}, t\right) \\
\ldots \\
x_{r}\left(s_{r}, t\right)
\end{array}\right)
$$


$x-\bar{X}$ vector coordinate dependence functions on $\bar{S}$ vector coordinates and on time;

$\bar{X}$ - building systems parameters signals vector;

$$
\bar{F}=\left(\begin{array}{c}
f_{1}\left(w_{1}, t\right) \\
f_{2}\left(w_{2}, t\right) \\
\ldots \\
f_{r}\left(w_{r}, t\right)
\end{array}\right)
$$

$f-\bar{F}$ vector ${ }^{-}$coordinate dependence functions on $\bar{W}$ vector ccordinates and on time;

$\bar{F}$ - disturbing actions signals vector;

Functional blocks of control signals generation provide simulation of the control signal generation process $(y)$. Control signals are generated based on state parameter signals $(x)$, disturbing actions signals $(f)$ and target parameters $\left(x_{u}\right)$. The data structure of the control signals generation functional block is shown in formulations $(4,5)$ :

$$
\begin{gathered}
R\left(\bar{X}-\bar{X}_{u}\right)+D \bar{Y}+E \bar{F}=p\left(\bar{X}-\bar{X}_{u}\right) \\
\bar{X}_{u}=\left(\begin{array}{c}
x_{u 1}\left(s_{u 1}, t\right) \\
x_{u 2}\left(s_{u 2}, t\right) \\
\ldots \\
x_{u r}\left(s_{u r}, t\right)
\end{array}\right)
\end{gathered}
$$

where $p$ - Laplace operator;

$\bar{S}_{u}=\left(\begin{array}{c}s_{u 1} \\ s_{u 2} \\ \ldots \\ s_{u r}\end{array}\right)$ - building systems target parameters vector;

$\bar{X}_{u}=\left(\begin{array}{c}x_{u 1} \\ x_{u 2} \\ \ldots \\ x_{u r}\end{array}\right)$ - building systems parameters target signals vector;

$\bar{Y}=\left(\begin{array}{c}y_{1} \\ y_{2} \\ \cdots \\ y_{d}\end{array}\right)-$ control signals vector;

$\bar{F}=\left(\begin{array}{c}f_{1} \\ f_{2} \\ \ldots \\ f_{z}\end{array}\right)$ - disturbing actions signals vector;

$R=\left(\begin{array}{ccc}r_{11} & \ldots & r_{1 r} \\ \ldots & \ldots & \ldots \\ r_{r 1} & \ldots & r_{r r}\end{array}\right)-$ building systems parameters signals matrix;

$D=\left(\begin{array}{ccc}d_{11} & \ldots & d_{1 d} \\ \ldots & \ldots & \ldots \\ d_{r 1} & \ldots & d_{r d}\end{array}\right)-$ control signals matrix

$E=\left(\begin{array}{ccc}e_{11} & \cdots & e_{1 z} \\ \ldots & \ldots & \ldots \\ e_{r 1} & \ldots & e_{r z}\end{array}\right)-$ disturbing actions signals matrix;

$x_{u 1}-\bar{X}_{u}$ vector coordinate dependence functions time dependence

on $\bar{S}_{u}$ vector coordinates and 
Functional blocks for controlling parameters are designed to simulate the process of converting control level signals to control actions affecting the state of CPBS physical level facilities (building systems). The considered functional blocks provide a simulation of the formation of data packets, time delays and distortions in the processes of information transfer.

Functional dependence of the parameters control functional block is as follows (6).

$$
\bar{U}=\left(\begin{array}{c}
u_{1}\left(y_{1}, t\right) \\
u_{2}\left(y_{2}, t\right) \\
\ldots \\
u_{d}\left(y_{d}, t\right)
\end{array}\right)
$$

where $u-\bar{U}$ vector coordinate dependence functions on $\bar{Y}$ vector coordinates and on time;

$\bar{U}-$ control actions vector.

The general CPBS data management model describes the processes implemented at the management level of each stage of the CPBS life cycle.

Collection, storage and processing of data on the current and past stages of the CPBS life cycle are carried out at the management level. The results of data processing at the management level, in particular, are implemented in the functioning order of the control level.

The block diagram of the CPBS data management general model, including 253 functional blocks, is shown in Fig. 2.

The functional block of computer-aided design of the CPBS data structures provides the processes of designing the CPBS data structures, including verification, as well as software and hardware. The functional block provides the formation of building systems parameters matrix $(A)$, control actions matrix $(B)$ and disturbing actions matrix $(C)$ by verifying formal dependencies between building systems parameters.

Also, the functional block of the computer-aided design of CPBS data structures provides the formation of building systems parameters signals matrix $(R)$ according to the formulation (7), control actions matrix $(K)$ according to the formulation (8) and disturbing actions signals matrix $(E)$ according to the formulation (9).

$$
R=\left(\begin{array}{ccc}
r_{11}\left(a_{11}\right) & \ldots & r_{1 r}\left(a_{1 r}\right) \\
\ldots & \ldots & \ldots \\
r_{r 1}\left(a_{r 1}\right) & \ldots & r_{r r}\left(a_{r r}\right)
\end{array}\right)
$$




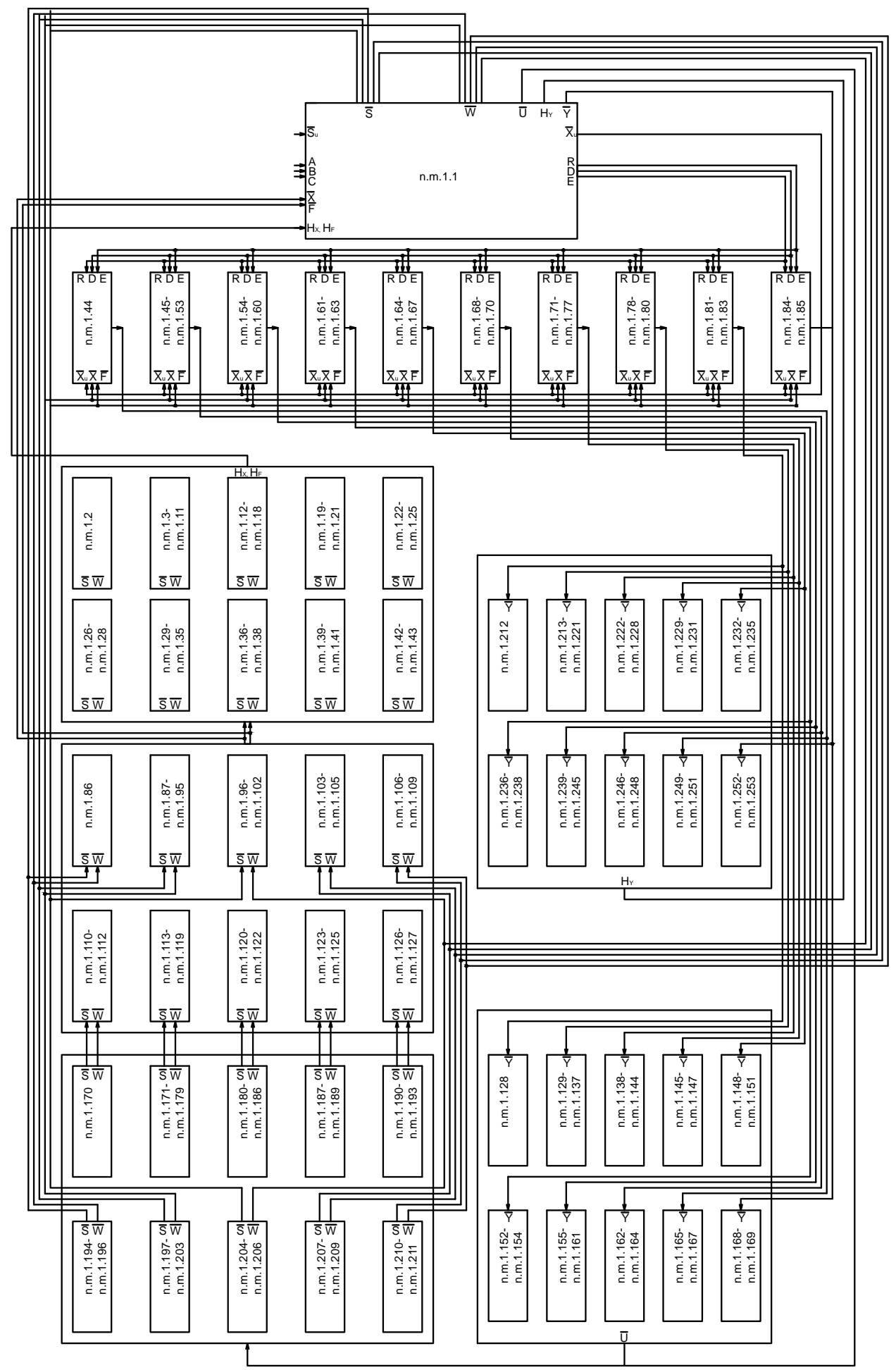

Fig. 2 CPBS data control general model 
where $r(a)$ - dependence functions of the building systems parameters signals matrix $(R)$ coefficients on the building systems parameters matrix $(A)$ coefficients.

$$
K=\left(\begin{array}{ccc}
k_{11}\left(b_{11}\right) & \ldots & k_{1 d}\left(b_{1 d}\right) \\
\ldots & \ldots & \ldots \\
k_{r 1}\left(b_{r 1}\right) & \ldots & k_{r d}\left(b_{r d}\right)
\end{array}\right)
$$

where $k(b)$ - dependence functions of the control signals matrix $(K)$ coefficients on the control actions matrix $(B)$ coefficients.

$$
E=\left(\begin{array}{ccc}
e_{11}\left(c_{11}\right) & \ldots & e_{1 z}\left(c_{1 z}\right) \\
\ldots & \ldots & \ldots \\
e_{r 1}\left(c_{r 1}\right) & \ldots & e_{r z}\left(c_{r z}\right)
\end{array}\right)
$$

where $e(c)$ - dependence functions of the disturbing actions signals matrix $(E)$ coefficients on the disturbing actions matrix $(C)$ coefficients.

The data sources for the functional block under consideration are the above building system parameters vector $(\bar{S})$, control actions vector $(\bar{U})$, disturbing actions vector $(\bar{W})$, building systems parameters signals vector $(\bar{X})$, building systems parameters target signals vector $\left(\bar{X}_{u}\right)$, control signals vector $(\bar{Y})$ and disturbing actions signals vector $(\bar{F})$

Functional blocks for determining the scope of information calculate the scope of information flows $H_{\bar{X}}$ according to building systems parameters signals vector $(\bar{X}), H_{\bar{Y}}$ according to control signals vector $(\bar{Y})$ and $H_{\bar{F}}$ according to disturbing actions signals vector $(\bar{F})$.

Functional blocks of the formation of control signals simulation provide the formation of control signals vector $(\bar{Y})$ on the basis of the generated in the functional block of computer-aided design of CPBS data structures of the building systems parameters signals matrix $(R)$, control signals matrix $(K)$ and disturbing actions signals matrix $(E)$, and also building systems parameters signals vector $(\bar{X})$ or building systems parameters imported signals values vector $\left(\overline{X^{o}}\right)$, building systems parameters target signals vector $\left(\bar{X}_{u}\right)$ or building systems parameters target signals imported values vector $\left(\overline{X_{u}^{o}}\right)$, control signals vector $(\bar{Y})$ or control signals imported values vector $\left(\overline{Y^{0}}\right)$ and disturbing actions signals vector $(\bar{F})$ or disturbing actions signals imported values vector $\left(\overline{F^{o}}\right)$.

The data structure of the functional block for simulating the generation of control signals may be (10) - (17).

$$
\begin{gathered}
R\left(\bar{X}-\bar{X}_{u}\right)+K \bar{Y}+E \bar{F}=p\left(\bar{X}-\bar{X}_{u}\right) \\
R\left(\bar{X}-\bar{X}_{u}\right)+K \bar{Y}+E \overline{F^{o}}=p\left(\bar{X}-\bar{X}_{u}\right) \\
R\left(\bar{X}-\overline{X_{u}^{o}}\right)+K \bar{Y}+E \bar{F}=p\left(\bar{X}-\overline{X_{u}^{o}}\right) \\
R\left(\bar{X}-\overline{X_{u}^{o}}\right)+K \bar{Y}+E \overline{F^{o}}=p\left(\bar{X}-\overline{X_{u}^{o}}\right) \\
R\left(\overline{X^{o}}-\bar{X}_{u}\right)+K \bar{Y}+E \bar{F}=p\left(\overline{X^{o}}-\bar{X}_{u}\right) \\
R\left(\overline{X^{o}}-\bar{X}_{u}\right)+K \bar{Y}+E \overline{F^{o}}=p\left(\overline{X^{o}}-\bar{X}_{u}\right) \\
R\left(\overline{X^{o}}-\overline{X_{u}^{o}}\right)+K \bar{Y}+E \bar{F}=p\left(\overline{X^{o}}-\overline{X_{u}^{o}}\right) \\
R\left(\overline{X^{o}}-\overline{X_{u}^{o}}\right)+K \bar{Y}+E \overline{F^{o}}=p\left(\overline{X^{o}}-\overline{X_{u}^{o}}\right)
\end{gathered}
$$

Functional blocks for simulating the monitoring of the parameters of building systems ensure the formation of a building systems parameters signals vector $(\bar{X})$ and disturbing 
actions signals vector $(\bar{F})$ based on the values of the building systems parameters vector $(\bar{S})$ and the disturbing actions vector $(\bar{W})$ received from the building systems simulation functional blocks.

Functional blocks of the building systems parameters control simulation provide the formation of the control actions vector $(\bar{U})$ based on the values of the control signals vector $(\bar{Y})$ or of the control signals imported values vector $\left(\overline{Y^{o}}\right)$. Thus, the considered functional block can have a functional dependence of the type (18) or (19).

$$
\begin{gathered}
\bar{U}=\left(\begin{array}{c}
u_{1}\left(y_{1}, t\right) \\
u_{2}\left(y_{2}, t\right) \\
\ldots \\
u_{r}\left(y_{r}, t\right)
\end{array}\right) \\
\bar{U}=\left(\begin{array}{c}
u_{1}\left(y_{1}^{o}, t\right) \\
u_{2}\left(y_{2}^{o}, t\right) \\
\ldots \\
u_{i r}\left(y_{r}^{o}, t\right)
\end{array}\right)
\end{gathered}
$$

Functional blocks of building systems simulation provide the formation of the building systems parameter signals vector $(\bar{S})$ and the disturbing actions vector $(\bar{W})$ in accordance with the control actions vector $(\bar{U})$.

The given models of the CPBS data exchange and control describe the processes implemented at each stage [15-20] of the CPBS life cycle. The functional blocks of the models under consideration allow us to describe the processes of data collecting, storing and processing on the current and past stages of the CPBS life cycle.

Thus, the given models are elements of the mathematical support of the CPBS design processes, determining the processes of information exchange and control between the CPBS structures of different levels of the hierarchy of the full life cycle.

This work was financially supported by the Ministry of Science and Higher Education (state task \# 7.6932.2017/8.9). All tests were carried out using research equipment of The Head Regional Shared Research Facilities of the Moscow State University of Civil Engineering.

\section{References}

1. K. Maincer Investigating the complexity: from artificial life and artificial intelligence to cyberphysical systems // Philosofiya nauki i tehniki - 2015. - 2. - Vol. 20. - pp. 85-105.

2. A. Volkov Cybernetics of building systems. Cyberphysical building systems // Promyshlennoe i gragdanskoe stroitelstvo - 2017. - 9. - pp. 4-7.

3. V. Kupriyanovskiy, D. Namiot, S. Sinyagov Cyber-physical systems as the basis of the digital economy // International journal of open information technologies - 2016. - 2. Vol. 4. - pp. 18-25.

4. A. Volkov Basics of homeostatics of buildings and structures // Promyshlennoe i gragdanskoe stroitelstvo. - 2002. - №1, - pp. 34-35

5. A. Volkov Systems of active security of building objects // Gilishchnoe stroitelstvo. 2000. - 7. - pp.13

6. A. Volkov Homeostat in Construction: A Systems Approach to Management Methodology // Promyshlennoe i gragdanskoe stroitelstvo. 2000 - 6. - C. 68.

7. A. Volkov Cybernetics of engineering functional systems // Sbornik dokladov XIII Rossiysko-polsko-slovackogo seminara "Teoreticheskie osnovy stroitelstva". M.: MGSU, - 2004. - pp. 317-322. 
8. P. Chelyshkov Cyberphysical integration of building systems // Estestvennye i tehicheskie nauki. - 2018. - 6. - pp.198-200

9. V. Shkodyrev Management in technical systems: from mechatronics to cyberphysical systems // Sbornuk dokladov nauchnogo foruma s megdunarodnym uchastiem "Nedelya nauki SPBPU" - 2014. - pp. 269-274.

10. N.P. Chetverik Life cycle of technosphere objects on the basis of innovative solutions // Nauka i bezopasnost - 2013. - 4 (9). - pp. 57-91.

11. K. Losev Creation and implementation of technology for managing the life cycle of construction sites // Promyshlennoe i gragdanskoe stroitelstvo - 2014. - №11. - pp. 8083.

12. A. Dobrynin and others. Digital Economy - Different Ways to Effectively Apply Technology (BIM, PLM, CAD,IoT, Smart City, BIG DATA and other) // International Journal of Open Information Technologies. - 2016. - Vol. 4. - 1. - pp.4-11.

13. D. Namiot Smart Cities 2016 // International Journal of Open Information Technologies. - 2016. - Vol. 4. - 1. - pp. 1-

14. V. Kupriyanovskiy, D. Namiot, P. Kupriyanovskiy Standardization of Smart Cities, Internet of Things and Big Data. Considerations for practical use in Russia. International Journal of Open Information Technologies. - 2016. - 2. - pp.34-40.

15. Ginzburg A.V. Information model of the life cycle of a building object / Promyshlennoe i gragdanskoe stroitelstvo, $-2016,-9-$ pp.61-65.

16. Ginzburg A.V. BIM-technologies during the life cycle of a building object / Informacionnye resursy Rossii, - 2016. - 5 - pp.28-31.

17. Ginzburg A.V., Shilova L.A., Shilov L.A. Modern standards of information modeling in construction / Nauchnoe obozrenie, - 2017. - №9 - pp.6-20.

18. Ginzburg A.V., Kogevnikov M.M. Improvement of the organization of construction of bridge structures on the basis of information modeling / Vestnik BGTU im. V.G. Shuhova, $-2017 .-8-$ pp.52-56.

19. Kogevnikov M.M., Ginzburg A.V., Kogevnikova S.T. Modern directions of information modeling in the aspect of road construction / Transportnoe delo Rossii, - 2017. - 3 pp.67-69.

20. Kogevnikov M.M., Ginzburg A.V., Kogevnikova S.T. Prospects for the development of information modeling in bridge construction / Nauka i biznes: puti razvitiya, -2017 . -8 - pp.22-27. 